\title{
Acute Lung Injury in Rat Caused by Immunoglobulin A Immune Complexes
}

\author{
Kent J. Johnson, Barny S. Wilson, Gerd O. Till, \\ and Peter A. Ward \\ Department of Pathology, University of Michigan Medical \\ School, Ann Arbor, Michigan 48109
}

bstract. Mouse IgG and IgA, with reactivity to dinitrophenol conjugated to carrier protein, have been isolated from myeloma proteins by means of a variety of affinity techniques. The IgA was predominantly in the dimeric form. The in vitro and in vivo biological activities of IgA-containing immune complexes were assessed in the rat.

IgA-containing immune complexes were demonstrated, in a dose-dependent manner in vitro, to activate neutrophils and to generate $\mathrm{O}_{2}^{\dot{-}}$. In addition, these immune complexes showed evidence of complement activation in vitro, by the use of immunofixation techniques. When IgA was instilled into the airways of rats and antigen was injected intravenously, acute lung injury occurred, as reflected by increases in lung permeability and morphological changes consisting of blebbing of endothelial cells, intra-alveolar hemorrhage, and fibrin deposition. The lung changes were directly proportional to the amount of $\operatorname{IgA}$ instilled into the airways and failed to occur if intravenous injection of antigen was omitted. Lung injury did not occur in animals that received an intravenous injection of antigen in the absence of an airway injection of IgA. Lung injury related to IgA-containing immune complexes was complement dependent but neutrophil independent. In companion studies with mouse IgG-containing immune complexes, acute lung injury also occurred and had morphological features similar to those associated with IgA-induced lung injury except that, in the case of IgG immune 'complex-induced damage, neutrophils were more evident. Acute lung injury induced by IgG-containing immune complexes, whether of mouse or rabbit origin, was complement and neutrophil dependent. The similarities and differences between IgG- and

Received for publication 25 October 1983 and in revised form 17 April 1984.

J. Clin. Invest.

(c) The American Society for Clinical Investigation, Inc.

$0021-9738 / 84 / 08 / 0358 / 12 \$ 1.00$

Volume 74, August 1984, 358-369
IgA-associated acute immune complex-induced injury of rat lung were reinforced by the use of morphometry techniques.

Studies with another monoclonal IgA antibody-containing antigen-binding activity to phosphorylcholine also demonstrated the ability of $\operatorname{IgA}$ antibody to cause acute lung injury in the rat. Neither antibody alone nor antigen (phosphorylcholine linked to bovine serum albumin) alone produced evidence of lung injury.

These studies indicate for the first time that immune complexes containing IgA have lung-damaging properties and that the pathogenic mechanisms are different from those associated with IgG-associated immune complexinduced acute lung injury.

\section{Introduction}

During the last few years there has been an expanding body of information that indicates the phlogistic potential of immune complexes in initiating inflammatory reactions in the lung. Increasing evidence suggests a role for immune complexes in human pulmonary diseases such as the idiopathic interstitial pneumonias (1-2) and in collagen vascular diseases such as systemic lupus erythematosus (3). Experimentally, numerous studies using polyclonal IgG immune complexes have clearly shown the ability of these complexes to induce acute lung injury that is complement- and neutrophil-dependent (4-6) and linked to the generation of oxygen-free radicals from neutrophils (7).

Whereas good experimental evidence that IgG immune complexes are tissue damaging exists, the same cannot be said for IgA. Although IgA is present in high concentrations in mucosal secretions, including bronchial fluids, no direct evidence is present to suggest that IgA may have pathogenic potential. On the other hand, there is some evidence to suggest that $\operatorname{IgA}$ may be pathogenic in the kidney and in blood vessels. Based on observations in human diseases, IgA and the third component of complement $(\mathrm{C} 3)^{1}$ deposits have been identified in the glomerular mesangium of patients with Berger's IgA nephropathy (8) and in vessels, as well as glomeruli, of individuals with Hen-

1. Abbreviations used in this paper: $\mathrm{C} 3$, third component of complement; ConA, concanavalin A; DNP, dinitrophenol. 
och-Schönlein purpura (9). Experimentally, the vascular infusion into mice of preformed immune complexes containing IgA reportedly causes a mild acute nephropathy, as reflected by the development of a transient hematuria (10). Finally, oral immunization of mice with bovine gamma globulin results in the mesangial deposition of immune complexes that contain IgA and the antigen, bovine gamma globulin, indicating that renal deposits of IgA may be the result of local, gut-associated immune responses to oral antigen (11).

The studies to be presented indicate that IgA-containing immune complexes can cause acute injury in rat lung. Furthermore, the mediator requirements for this type of acute lung injury are clearly different from those for the lung injury caused by the deposition of IgG-containing immune complexes. The data to be presented may bear a relationship to observations made in humans who show evidence of glomerular or vascular injury associated with immune complex deposits containing IgA and $\mathrm{C} 3$.

\section{Methods}

Animal model. Young adult 250-g male Long-Evans rats (Charles River Breeding Laboratories, Inc., Wilmington, MA) were used in these studies. Under ketamine anesthesia, tracheostomy was performed and the antibody (mouse monoclonal IgG or IgA with anti-dinitrophenol (DNP) activity or rabbit IgG polyclonal antibody to bovine serum albumin [BSA]) in a volume of $0.25 \mathrm{ml}$ in phosphate-buffered saline (PBS) (pH 7.4) was injected into the airways during inspiration via a fine teflon catheter. The catheter was then removed and the incision was closed with silk suture. The DNP-BSA antigen at a dose of $3.3 \mathrm{mg}$ was then injected intravenously.

Pulmonary injury. The resulting pulmonary injury was quantitated by previously described methods $(4,7)$. Briefly, $1 \mu \mathrm{g}$ BSA (labeled with ${ }^{125}$ I) was injected intravenously with the antigen. After $4 \mathrm{~h}$ the animals were killed by an intraperitoneal injection of ketamine followed by transection of the vena cava. Exactly $1.0 \mathrm{ml}$ of blood was collected and the amount of radioactivity was assessed. Then the trachea and mediastinal contents were removed en bloc and $10 \mathrm{ml}$ of saline was perfused through the right ventricle of the still-pumping heart to remove blood remaining in the pulmonary vascular system. The lung perfusate was allowed to exit from the aortic arch. Remaining radioactivity in the lung which represented extravascular albumin was then measured in a crystal scintillation counter. The ratio of this value to the amount of radioactivity in $1.0 \mathrm{ml}$ blood was calculated as a measurement of lung injury.

Neutrophil depletion procedures. Rats were depleted of circulating blood neutrophils by the intraperitoneal injection of $1.0 \mathrm{ml}$ serum obtained from rabbits immunized with rat neutrophils (4). $12 \mathrm{~h}$ later (when the animals were used for the experiments) there were $<500$ neutrophils/ $\mathrm{ml}$ blood as defined by total and differential blood cell counts. This compares with a typical neutrophil count assessed in 10 normal rats of $3,809 \pm 228$ cells $/ \mathrm{mm}^{3}$ (mean $\pm \mathrm{SEM}$ ). The numbers of mononuclear cells (lymphocytes and monocytes) and platelets were not affected by this treatment.

Complement depletion procedures. In studies where the role of the complement system in lung injury was assessed, selective complement depletion was accomplished by the administration of purified cobra venom factor as originally described by Cochrane et al. (12). Cobra venom factor administration caused a nearly total depletion of C3 (with $<5 \%$ remaining as determined immunochemically), thus blocking activation of both the classical and alternative pathways of the complement system.

Morphologic studies. At the time of death, fresh lung tissue was processed for immunofluorescence examination and for transmission electron microscopy. For immunofluorescence, the tissue was snap-frozen in liquid nitrogen, and lung sections were stained for the presence of IgA. For electron microscopy studies, the lungs were inflated with glutaraldehyde, and after fixation, ultrathin sections were obtained and processed for ultrastructural analysis.

Morphometric studies of lung. Plastic embedded sections ( $1 \mu \mathrm{m}$ thick) of lung tissue stained with toluidine blue were obtained from animals treated with the various reagents listed above. 30 different interstitial capillaries and alveoli from each of three rats per group were examined by morphometric techniques. These structures had been randomly selected for analysis with a photoscope II with a $40 \times$ objective (Carl Zeiss, Inc., New York). This instrument was connected electronically to a high resolution television camera which in turn was linked to a Video-Plan (Carl Zeiss, Inc.) that contained a television screen. The instrument was programmed to permit measurement of: $(a)$ the length of endothelial surfaces in interstitial capillaries; $(b)$ the amount of the surface involved with bleb formation; $(c)$ the number of neutrophils within capillaries; $(d)$ the length of alveolar surfaces; and $(e)$ the numbers of erythrocytes within alveolar compartments. Areas to be measured were outlined on the television screen with an electronic wand and the measurements fed into a computer for analysis. Further details of these techniques are provided in a recent publication (13).

In vitro studies with IgA and rat neutrophils. Peritoneal neutrophils were harvested from rats that received $30 \mathrm{ml}$ of $1 \%$ glycogen (Sigma Chemical Co., St. Louis, MO) in PBS $4 \mathrm{~h}$ earlier. These cells, of which $\mathbf{9 8 \%}$ were neutrophils, were then incubated with preformed immune complexes containing DNP-BSA and IgA antibody (obtained by affinity chromatography). The amount of superoxide $\left(\mathrm{O}_{2}^{\dot{*}}\right)$ produced by $2 \times 10^{6}$ cells was determined by techniques recently described in detail (14).

Measurement of complement activation by immunofixation. Complement activation was assessed by immunofixation techniques. The general procedures as outlined by Ritchie and Smith (15) were used. $200 \mu \mathrm{l}$ of fresh human serum were incubated for $30 \mathrm{~min}$ at $37^{\circ} \mathrm{C}$ with various reagents. Controls included the addition of antigen or antibody alone or the incubation with zymosan particles. After incubation, EDTA was added to each sample (final concentration $12 \mathrm{mM}$ ) and portions of each sample were loaded onto an $0.8 \%$ agarose gel. This gel was then subjected to electrophoresis with a multiphor electrophoresis unit (LKB Instruments, Inc., Gaithersburg, MD) at a setting of $20 \mathrm{~V} / \mathrm{cm}$ for 60 min. After this, the gel was overlaid with goat antihuman C3 antibody and incubated for $60 \mathrm{~min}$. The gel was then washed several times in $1.5 \% \mathrm{NaCl}$ and stained with Coomassie Blue. After they were destained and dried, the protein bands were analyzed by optical scanning with an automatic computing densitometer (ACD-18; Gelman Sciences Inc., Ann Arbor, MI), which automatically measured the percentage conversion of native $\mathrm{C} 3$ to $\mathrm{C} 3 \mathrm{~b}$.

Preparation of DNP-BSA. DNP-BSA was prepared by the reaction of 2,4-dinitrobenzenesulfonic acid (Eastman Laboratory and Specialty Chemicals, Eastman Kodak Co., Rochester, NY) with BSA (Sigma Chemical Co.) overnight at room temperature according to the method of Eisen (16). After extensive dialysis to remove the unconjugated DNP, the number of DNP groups per molecule of BSA was calculated spectrophotometrically at $360 \mathrm{~nm}$. The BSA content was quantitated by 
absorption at $280 \mathrm{~nm}$. The final preparation contained an average of 50 DNP groups/molecule of BSA.

Preparation of rabbit polyclonal IgG antibody. Polyclonal IgG antibody to BSA was obtained by hyperimmunization of outbred male New Zealand rabbits. The resulting serum was purified by standard anionic exchange techniques to obtain the IgG fraction that was rich in precipitating activity to BSA. Details of this preparation are contained in an earlier report (4). The ability of this antibody to produce acute lung injury was compared with the lung-damaging activities of murine monoclonal antibodies (reactive to DNP-BSA) of the IgG and IgA classes.

IgA plasmacytomas. The murine plasmacytomas, XRPC 25, MOPC 460 , and MOPC 315 , which secrete IgA myeloma proteins that bind to DNP- and trinitrophenyl-substituted proteins, were kindly provided by Litton Bionetics (Kensington, MD) operating under National Cancer Institute (Bethesda, MD) contract N01-CB-25584 (directed by Dr. Michael Potter). Plasmacytomas were maintained by serial passage in $\mathrm{Balb} / \mathrm{c}$ mice previously inoculated intraperitoneally with $0.5 \mathrm{ml}$ pristane (Aldrich Chemical Co., Inc., Milwaukee, WI). Ascites-producing tumors usually developed within $14 \mathrm{~d}$. The ascites fluids obtained by paracentesis were allowed to clot in a glass tube overnight at $4^{\circ} \mathrm{C}$, minced with a razor blade, and then subjected to centrifugation to obtain cell-free material for purification.

Mc603 and T15 myeloma cell lines were gifts of Dr. Michael Potter (National Cancer Institute) and were the sources of IgA antibodies to phosphorylcholine. The IgA antibodies were purified by affinity chromatography and were kindly provided by Dr. J. L. Claflin (University of Michigan, Ann Arbor, MI). IgA antibody to phosphorylcholine has been characterized elsewhere $(17,18)$.

Purification of myeloma proteins. Ascites fluids were applied to Sepharose 4B (Pharmacia Fine Chemicals Inc., Piscataway, NJ) columns conjugated with DNP-substituted BSA through the cyanogen bromide reaction. After extensive washing with PBS until absorbance at $280 \mathrm{~nm}$ was not detectable, the bound proteins were eluted with $0.5 \mathrm{~N}$ acetic acid ( $\mathrm{pH} \mathrm{2.8)}$ and immediately neutralized (to $\mathrm{pH} 7.0$ ) with Tris buffer (pH 7.0). Analysis of purified antibodies by double diffusion with isotypespecific antibodies (Cappel Laboratories, Cochranville, PA) and by sodium dodecyl sulfate (SDS)-polyacrylamide gel electrophoresis showed that the MOPC 315 preparation contained only IgA, whereas MOPC 460 contained mainly IgA with small amounts of IgG, and XRPC 25 contained a mixture of IgG and IgA. A pure IgA anti-DNP antibody was subsequently obtained from the affinity-purified MOPC 460 antibody by adsorption-elution from concanavalin A (ConA) Sepharose, using 2\% alpha-methyl mannoside. In contrast, the IgG anti-DNP antibody from XRPC 25 ascites was isolated from the contaminant IgA by elution from Sepharose with $0.09 \mathrm{M}$ phosphate buffer ( $\mathrm{pH}$ 7.4) before affinity chromatography on DNP-BSA-Sepharose as described above.

Gel electrophoresis. Slab gels $(1.5 \times 160 \mathrm{~cm})$ containing $10 \%$ polyacrylamide ( 37 to 1 ratio of acrylamide to bis-acrylamide) were produced using the SDS discontinuous buffer system described by Laemmli (19). Samples $(100 \mu \mathrm{l})$ prepared in SDS buffer were subjected to electrophoresis at a constant current of $30 \mathrm{~mA}$ until the bromphenol-blue dye front reached the bottom of the gel. After electrophoresis, the gels were immediately fixed in 50\% methanol, $10 \%$ acetic acid, and $0.5 \%$ Coomassie Blue R250 for 30 minutes at $37^{\circ} \mathrm{C}$ and then destained overnight in a solution containing $10 \%$ methanol, $10 \%$ acetic acid. Molecular weight standards for the gels included myosin $(200,000), \beta$-galactosidase $(116,000)$, phosphorylase B $(92,000)$, bovine serum albumin $(68,000)$ and ovalbumin $(45,000)$.

Gel filtration. A $33 \times 1.5 \mathrm{~cm}$ glass column was packed with Sephacryl S300 (Pharmacia Fine Chemicals) according to the manufacturer's in- structions and then calibrated with the following standards: dextran blue 2000 (void volume), bovine catalase $(230,000 \mathrm{D})$, mouse $\operatorname{IgG}_{2 \mathrm{a}}(150,000$ D), bovine serum albumin $(68,000 \mathrm{D})$ and sodium dichromate (inclusion peak). For each analysis, the sample size added was $2.5 \mathrm{ml}$, the fraction size collected was $3 \mathrm{ml} /$ tube and the flow rate, maintained by a peristaltic pump, was $10 \mathrm{ml} / \mathrm{h}$. Relative elution points were calculated as the number of fractions between the peak protein fraction and the void volume divided by the number of fractions between the void volume and the inclusion volume.

\section{Results}

Electrophoretic characterization of the mouse monoclonal (MOPC) antibodies to DNP. Antibodies purified from ascites fluids were analyzed with isotype-specific antibodies by double diffusion in agar and by SDS-polyacrylamide gel electrophoresis. The results indicated that MOPC 315 contained only IgA, whereas MOPC 460 contained mainly IgA with small amounts of IgG; XRPC 25 contained mainly IgG with small amounts of IgA (data not shown). A homogeneous IgA anti-DNP was then obtained from affinity purified MOPC 460 antibody by adsorption elution from ConA-Sepharose, using $2 \%$ alphamethyl mannoside, as described earlier.

Analysis by SDS-slab gel electrophoresis (under reducing conditions) of XRPC IgG and MOPC $460 \mathrm{IgA}$ myeloma proteins isolated from ascites fluids by affinity chromatographic procedures is shown in Fig. 1. XRPC whole ascites fluid (lane 1a),

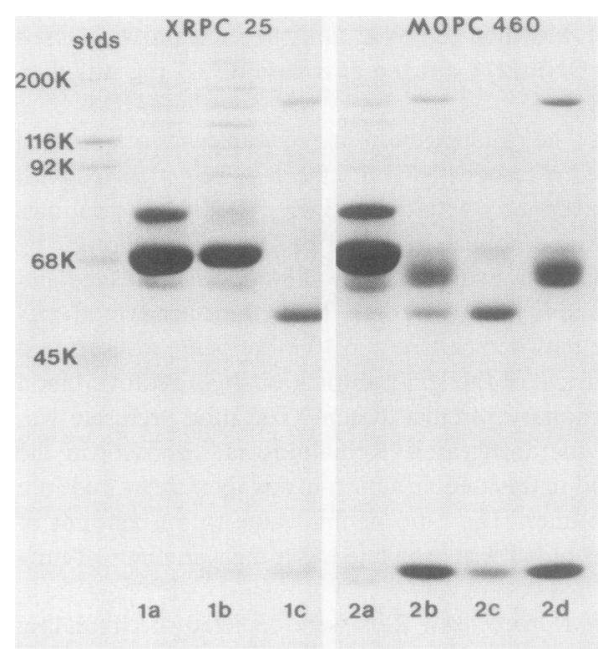

Figure 1. SDS slab gel electrophoresis of the murine IgG and IgA purified from myeloma proteins (XRPC 25 and MOPC 460). All preparations except standards (stds) were subjected to reducing conditions before electrophoresis. (1a) XRPC 25 ascites fluid. (1b) Ascites fluid after DEAE chromatography. (1c) Purified IgG after elution from a DNP-BSA-Sepharose column. (2a) MOPC 460 ascites fluid. (2b) Ascites fluid after affinity chromatography. (2c) Effluent from a ConASepharose column showing IgG. (2d) Purified IgA eluted from the ConA-Sepharose column. The fast-running bands represent light chains. 
which contained a mixture of IgG and IgA anti-DNP antibodies, was subjected to DEAE Sepharose chromatography to remove IgA and other proteins (lane $1 b$ ) prior to purification of the IgG antibodies on DNP-BSA linked to Sepharose beads and subsequent elutions under acidic conditions (lane $1 c$ ). This resulted in a reasonably homogeneous preparation of $\mathrm{IgG}$, as demonstrated by the gamma chain in lane $1 c$. MOPC 460 ascites (lane $2 a$ ), which contained mainly IgA anti-DNP and some IgG, was first purified by affinity chromatography on DNP-BSA-Sepharose, resulting in both IgA and IgG antibodies (lane $2 b$ ). The antibody mixture was then subjected to chromatography on ConA-Sepharose, resulting in an effluent (lane $2 c$ ) that contained mainly IgG anti-DNP and the retained material that was eluted by the addition of $2 \%$ alpha methyl-mannoside. The resulting material contained IgA anti-DNP antibody as assessed by the presence of alpha chain (lane $2 d$ ). (The bands at the bottom of the gel represent light chains from the reduced immunoglobulins.) The purified antibodies also contained small amounts of a contaminant protein with a molecular weight of $\sim 150,000$.

Immunoprecipitation of antibody preparations. Typical results from double diffusion in agar are shown in Fig. 2. In Fig. $2 A$, where the mouse IgA purified from MOPC 460 was analyzed, it was demonstrated that only alpha chains could be detected by immunoprecipitation, with no evidence of contamination by gamma or mu chains. In addition, antibody to whole mouse serum revealed a single band reactive with the IgA preparation. The other IgA and IgG preparations showed similar, expected patterns of homogeneity (data not shown). In Figure $2 B$, the ability of the IgA antibody preparations to form immune precipitates in the presence of antigen is also shown. IgA antibody was placed in the center well, increasing dilutions of antigen (DNP-BSA) in the outer wells. The amount of immunoprecipitation correlated directly with the amount of antigen present. Each of the IgA preparations revealed this type of precipitating activity in the presence of antigen. The IgG preparation from the mouse MOPC (XRPC) revealed only a faint precipitin pattern when similarly analyzed in gel.

Characterization of the IgA by gel filtration. IgA purified from MOPC 315 was passed through a Sephacryl S300 column, as outlined in Methods, in order to determine if the bulk of the antibody was present in the anticipated dimeric form. The IgA passed through the column in a narrow, sharply defined peak just after the dextran blue (elution at $6.0 \mathrm{ml}$ ). By the use of standards of known molecular weight for comparison, IgA protein peak had an estimated molecular weight of 363,000 . The other IgA preparations showed a similar pattern of elution. Thus, the IgA antibody used in all experiments was in the dimeric form.

In vitro biological activities of IgA complexes. By the use of anti-DNP preparation purified from MOPC 460 at a constant amount $(100 \mu \mathrm{g})$, antigen was added in various concentrations. As shown in the top of Fig. 3, turbidity developed as the ratio of antigen to antibody increased. This was indicative of precipitating immune complexes which formed over a rather wide range of antigen until very high concentrations of antigen (400$800 \mu \mathrm{g}$ ) were reached, at which point there was evidence of increasing solubilization of the complexes.

The ability of these complexes to interact with neutrophils and bring about their activation as measured by production of $\mathrm{O}_{2}^{-}$is shown in the bottom of Fig. 3. It can be seen that increasing amounts of antibody in the presence of antigen were able to activate neutrophils, leading to $\mathrm{O}_{2}^{\dot{1}}$ generation. The neutrophil activation was associated with the amount of antibody present in the complexes, as well as with the ratio of antigen to antibody, with increasing production of $\mathrm{O}_{2}^{\dot{*}}$ as the amount of antigen increased. These data suggest that both the insoluble complexes and those rendered more soluble in antigen excess were able to activate neutrophils to bring about $\mathrm{O}_{2}^{-}$generation.

Studies of the biological effects on rat neutrophils of $\operatorname{IgA}$ immune complexes were extended with the use of preformed IgA immune complexes with DNP-BSA as antigen (Fig. 4). These studies included complexes with three different ratios of antigen to antibody (1:1 to 4:1). The activation of neutrophils was directly proportional to the amount of complex added to the cells and was also affected by the ratio of antigen to antibody. Similar studies were carried out with rat alveolar macrophages, but the DNP alone caused nonspecific cell activation such that definitive studies with the immune complexes were impossible.

Complement fixation induced by IgA immune complexes. The next series of experiments was designed to determine if the
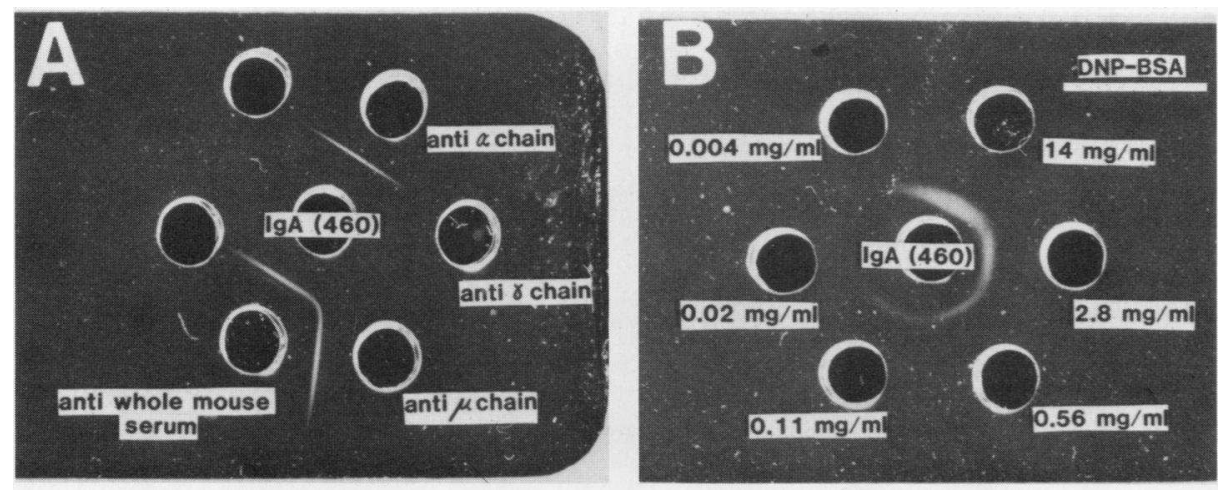

Figure 2. Double diffusion gel studies of an IgA preparation (purified from. MOPC-460). (A) Analysis for heavychain content of the IgA. $(B)$ The ability of $\operatorname{IgA}$ anti-DNP to form a precipitating complex in the presence of increasing amounts of antigen (DNP-BSA). 

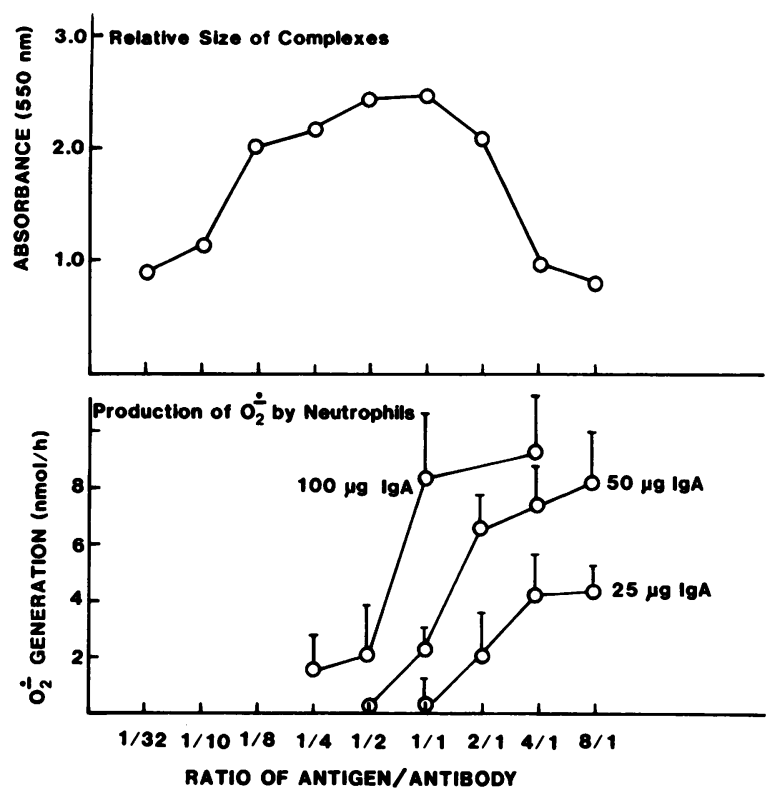

Figure 3. Ability of purified IgA (from MOPC 450) to form precipitates with increasing amounts of antigen added (top) and to activate rat neutrophils to generate $\mathrm{O}_{2}^{-}$(bottom).

IgA immune complexes could activate the complement system. The method of immunofixation was selected as a highly sensitive method for the detection of complement activation. Immune complexes were initially added to rat serum, but rat serum was found to undergo spontaneous activation at $37^{\circ} \mathrm{C}$, making it difficult to obtain adequate control values. Therefore, we turned to human serum because of its reliability for this technique. As shown in Table I, in which densitometric analyses of the gel patterns were obtained, human serum incubated at $37^{\circ} \mathrm{C}$ for 15 min showed a small amount of $\mathrm{C} 3 \mathrm{~b}$ formation $(10.1 \%$, Table

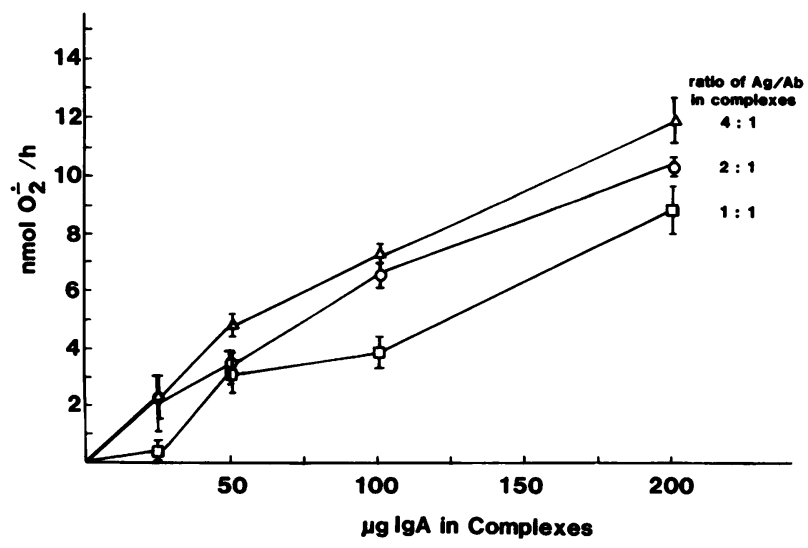

Figure 4. The ability of preformed IgA immune complexes to activate neutrophils based on the ratio of antigen to antibody and the amount of complex added.
I), with slightly more ( $16.1 \%) \mathrm{C} 3 \mathrm{~b}$ formed in serum incubated with $100 \mu \mathrm{g}$ IgA anti-DNP. Antigen alone in a dosage range from 10 to $50 \mu \mathrm{g}$ showed some complement activation with C3b, accounting for 32.7 to $33.5 \%$ of total C3 antigen (Table I). The addition of $100 \mu \mathrm{g} \operatorname{IgA}$ antibody to the same range of dosages of antigen revealed that, in the case of 25 and $50 \mu \mathrm{g}$ antigen, 86.7 and $87.2 \%$, respectively, of $C 3$ was in the converted (C3b) form. As a control, zymosan-activated serum resulted in $52.1 \%$ conversion of the $\mathrm{C} 3$. These data indicate that, given the appropriate conditions, immune complexes containing IgA antiDNP ultimately cause significant activation of complement as revealed by immunofixation.

Lung injury produced in vivo by IgA complexes. A series of rats was studied for the ability of increasing amounts of affinitypurified IgA (isolated from MOPC 460) antibody to DNP to produce acute lung injury. The antibody was instilled into the tracheobronchial tree while a constant amount $(3.3 \mathrm{mg})$ of antigen was injected intravenously. The data in Fig. 5 demonstrate a dose-response relationship and indicate that, as the amount of IgA antibody instilled into the lungs increased from $50 \mu \mathrm{g}$ to $250 \mu \mathrm{g}$, an increasing degree of lung injury occurred, as indicated by increased lung permeability. At dosages of IgA beyond $250 \mu \mathrm{g}$, little further increase in lung injury developed. That the lung injury was dependent on the intravenous injection of antigen was demonstrated by the fact that, in animals with 100,500 , or $750 \mu \mathrm{g} \mathrm{IgA}$ instilled into the tracheobronchial tree in the absence of an intravenous injection of antigen, lung injury was minimal, not exceeding a permeability value of 0.30 (Fig. 5). In data not shown, the intravenous injection and the airway instillation of saline resulted in a lung permeability value of $\mathbf{0 . 2 5}$.

Table I. Conversion of Human Serum C3 by IgA Immune Complexes

\begin{tabular}{lll}
\hline & \multicolumn{2}{l}{ Status of $\mathrm{C3}$} \\
\cline { 2 - 3 } Material added to serum ${ }^{*}$ & $\mathrm{C} 3$ & $\mathrm{C} 3 \mathrm{~b}$ \\
\hline & $\%$ & $\%$ \\
None & 89.9 & 10.1 \\
IgA $(100 \mu \mathrm{g})$ & 83.9 & 16.1 \\
DNP-BSA $(10 \mu \mathrm{g})$ & 68.3 & 32.7 \\
$\quad(25 \mu \mathrm{g})$ & 66.5 & 33.5 \\
$\quad(50 \mu \mathrm{g})$ & 67.2 & 32.8 \\
IgA $(100 \mu \mathrm{g})+\mathrm{DNP}-\mathrm{BSA}(10 \mu \mathrm{g})$ & 82.7 & 17.3 \\
IgA $(100 \mu \mathrm{g})+\mathrm{DNP}-\mathrm{BSA}(15 \mu \mathrm{g})$ & 13.3 & 86.7 \\
IgA $(100 \mu \mathrm{g})+$ DNP-BSA $(50 \mu \mathrm{g})$ & 12.8 & 87.2 \\
Zymosan & 47.9 & 52.1 \\
\end{tabular}

* Material added (in a volume of $100 \mu$ l) to $200 \mu \mathrm{l}$ fresh human serum, followed by incubation at $37^{\circ} \mathrm{C}$ for $15 \mathrm{~min}$. 


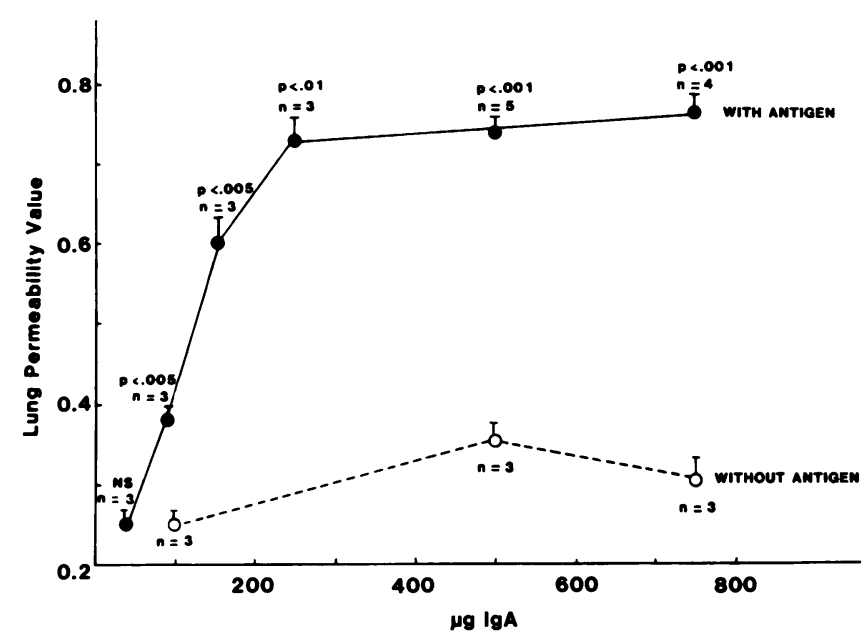

Figure 5. Acute lung injury (as defined by increased lung permeability) produced by the airway instillation of increasing amounts of IgA and a constant amount of antigen $(3.3 \mathrm{mg})$ injected intravenously. Bars indicate standard errors of the mean.

Lung permeability changes were also assessed in 10 rats that received an intravenous injection of antigen ( $3.3 \mathrm{mg} \mathrm{BSA})$ and $0.3 \mathrm{ml}$ saline into the airways. The individual lung permeability values were $0.28,0.21,0.25,0.29,0.20,0.21,0.25,0.21,0.29$, and 0.25 , with a mean \pm SEM of $0.29 \pm 0.06$. These data indicate that intravenous injection of antigen in the absence of antibody does not lead to evidence of lung injury.

Detailed morphological studies were carried out (Fig. 6). $A$ reveals a section of lung from a rat receiving $600 \mu \mathrm{g}$ affinitypurified IgA into the airways when the intravenous injection of antigen was omitted. As shown by transmission electron microscopy, there was no indication of lung injury. The alveolar spaces were without evidence of hemorrhage or exudate. In $B$, frozen section analysis was carried out on the lung of an animal that received airway instillation of $600 \mu \mathrm{g} \mathrm{IgA}$ antibody and the intravenous infusion of $3.3 \mathrm{mg}$ DNP-BSA. This section was stained for the presence of mouse $\operatorname{IgA}$ and demonstrates the deposition of $\operatorname{IgA}$ on and within alveolar septae. In $C$ and $D$, transmission electron micrographs on companion sections of lung from animals injured with IgA immune complexes demonstrate the presence of intra-alveolar hemorrhage and fibrin deposition with few, if any, neutrophils present. In $D$ and $F$, the arrows indicate vascular endothelial cell injury as defined by blebbing. Higher magnification of lungs injured by IgA immune complexes reveal the presence of fibrin and erythrocytes within alveolar spaces $(E) . F$ demonstrates at higher magnification the extensive blebbing of vascular endothelial cells in the pulmonary interstitial capillaries.

To determine if IgA of a different antigen-binding specificity (other than DNP) had the potential to cause acute lung injury in the rat, the experiments described in Table II were carried out. Two different IgA antibodies (T15 and McPC603), each with reactivity to phosphorylcholine, were employed by the instilling of $600 \mu \mathrm{g}$ into the airways. This was followed by the intravenous injection of $4.0 \mathrm{mg} \mathrm{BSA}$-phosphorylcholine. In all other respects the protocols were similar to those described in Fig. 5. As shown in Table II, in 13 animals the IgA antibodies to phosphorylcholine in the presence of injected antigen produced lung permeability values $(0.61 \pm 0.05$ and $0.51 \pm 0.04)$ that were double the values for animals receiving antibody into the airways in the absence of intravenously injected antigen $(0.29 \pm 0.01)$. Animals injected intravenously with $4.0 \mathrm{mg}$ BSAphosphorylcholine and with saline instillation into the airways also showed low lung permeability values $(0.31 \pm 0.01)$. These data indicate that acute lung injury in rats can be produced with IgA antibody to phosphorylcholine.

Lung injury produced in vivo by IgG immune complexes. Studies, similar to those described above, were carried out with affinity-purified murine IgG isolated from myeloma XRPC. IgG was instilled into the tracheobronchial tree while $3.3 \mathrm{mg}$ DNPBSA was injected intravenously. Evidence of lung damage as reflected by permeability values is demonstrated in Fig. 7. Acute lung damage occurred in a manner that was directly proportional to the amount of IgG instilled into the airways. In the absence of antigen, little change in lung permeability occurred, in spite of increasing amounts of IgG instilled into the airways (Fig. 7, broken line). Thus, monoclonal IgG immune complexes, like monoclonal IgA immune complexes, produce acute lung injury in rats in direct proportion to the amount of antibody instilled into the airways.

Morphological features by transmission electron microscopy of animals with acute lung injury due to IgG anti-DNP complexes are shown in Fig. $8, A$ and $B$. Extensive intra-alveolar hemorrhage and protein exudation were present, along with numerous neutrophils, many of which were still within the vascular compartment (Fig. $8 \mathrm{~A}$, open arrows). Evidence of blebbing of vascular endothelial cells was also apparent (Fig. $8 \mathrm{~B}$, closed arrows).

Mediator requirements for IgA- and IgG-induced immune complex injury of lung. The data in Table III represent a composite of experimental observations in which lung injury was produced by the use of either mouse monoclonal IgA or IgG antibody to DNP, or rabbit polyclonal IgG antibody to BSA. The role of neutrophils and complement was investigated in each of the experimental models.

By means of IgA anti-DNP antibody purified from MOPC 460 , significant acute lung injury was induced in normal rats (Table III, experiment A), as contrasted with those animals in which the intravenous injection of antigen was omitted (Table III, experiment B). The mean lung permeability values of the two groups were $0.74 \pm 0.04$, as compared with $0.35 \pm 0.02$, respectively. In companion animals that were neutrophil-depleted by the use of specific antibody, the lung permeability values were not distinguishably different from those animals that were neutrophil intact (mean lung permeability values of $0.71 \pm 0.01$ vs. $0.74 \pm 0.01$, respectively) (Table III, experiment A). Antigen 


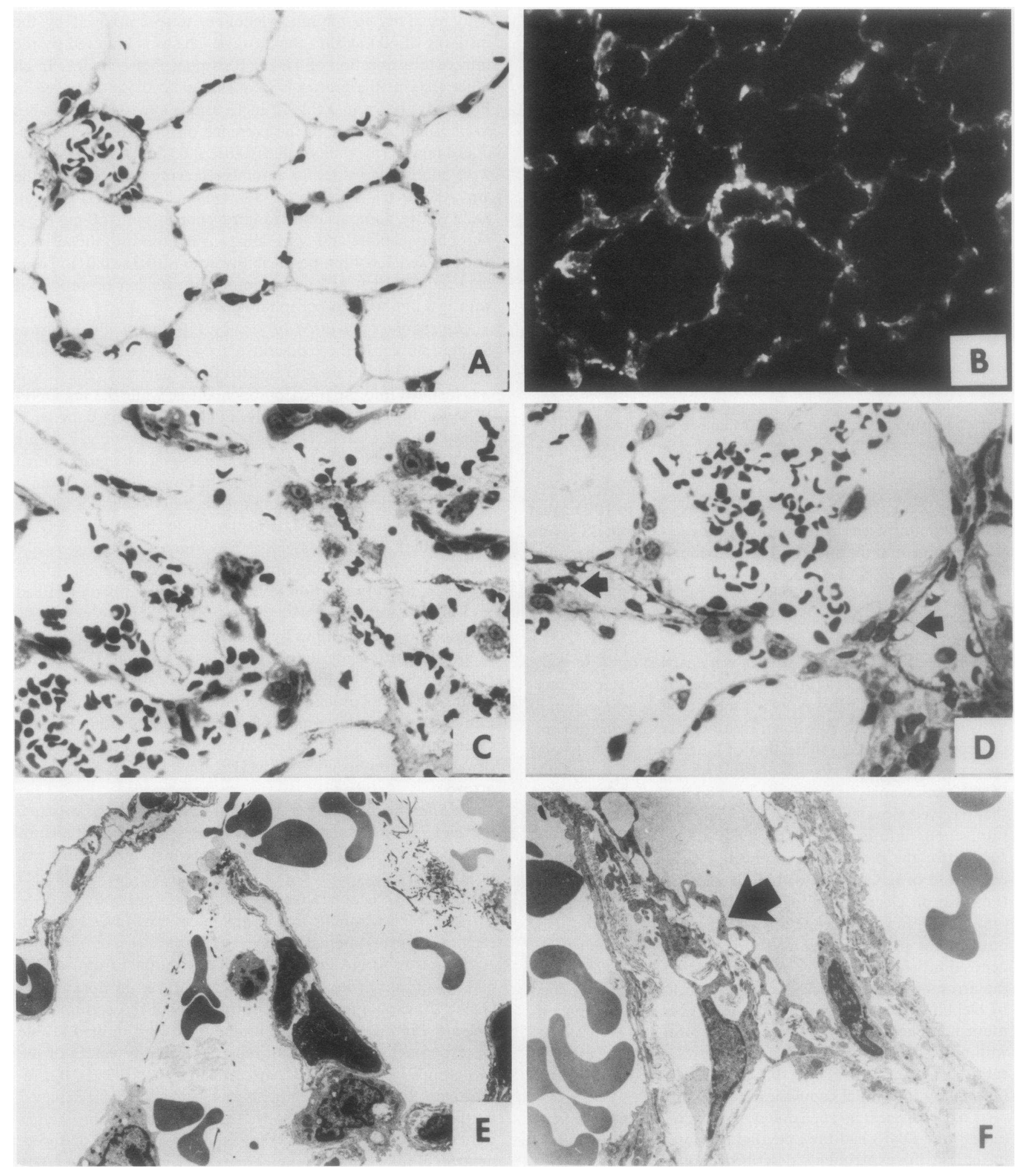


Table II. Lung Injury Produced by IgA Antibody to Phosphorylcholine

\begin{tabular}{|c|c|c|c|}
\hline \multirow{2}{*}{$\begin{array}{l}\text { Antibody injected } \\
\text { into airways } \\
\text { ( } 600 \mu \mathrm{g} \text { protein) }\end{array}$} & \multirow{2}{*}{$\begin{array}{l}\text { Antigen } \\
\text { injected } \\
\text { intravenously* }\end{array}$} & \multicolumn{2}{|l|}{ Lung permeability valuesł } \\
\hline & & Individual values & Mean \pm SEM \\
\hline & $m g$ & & \\
\hline IgA, T15 & 4.0 & $\begin{array}{c}0.50,0.74,0.62,0.46 \\
0.55,0.86,0.51\end{array}$ & $0.61 \pm 0.05$ \\
\hline IgA, McPC 603 & 4.0 & $\begin{array}{l}0.48,0.40,0.63,0.51 \\
0.62,0.41\end{array}$ & $0.51 \pm 0.04$ \\
\hline $\operatorname{IgA}, \mathrm{T} 15$ & None & $0.32,0.28$ & $0.29 \pm 0.01$ \\
\hline None & 4.0 & $0.31,0.32$ & $0.31 \pm 0.01$ \\
\hline
\end{tabular}

* Antigen consisted of phosphorylcholine linked to BSA.

$\ddagger$ Lung injury is expressed as lung permeability values, as described in the text.

deprived but neutrophil-intact animals that received the same dose of $\operatorname{IgA}$ antibody into the lungs showed a value of $0.35 \pm 0.02$, whereas neutrophil depleted animals treated similarly had a mean lung permeability of $0.25 \pm 0.01$ (Table III, experiment B). In complement-depleted animals, which received IgA antibody into the airways and antigen intravenously, a lung permeability value of $0.49 \pm 0.03$ was measured, indicating a $65 \%$ reduction in lung permeability when compared with complement-intact animals (Table III, experiment A).

These findings were extended by the use of another monoclonal IgA anti-DNP antibody (MOPC 315) in which lung permeability values reached a mean value of $0.61 \pm 0.03$ in animals injected with antibody into the airways and with antigen into the vasculature, as contrasted with antigen deprived animals in which the same amount of antibody instilled into the airways produced a lung permeability value of $0.27 \pm 0.01$ (Table III, experiments $\mathrm{C}$ and $\mathrm{D})$. In a parallel series of animals that were complement depleted, a significant reduction in lung damage was noted in animals receiving both antigen and antibody, with a lung permeability value of $0.43 \pm 0.02$ (Table III, experiment C). This represents a 53\% reduction in the amount of lung damage produced by IgA immune complexes in animals that are complement depleted.

These studies were extended using airway instillation of IgG murine monoclonal anti-DNP isolated from XRPC myeloma. When antigen was injected intravenously, the mean lung permeability value in 10 animals was $0.62 \pm 0.03$, as contrasted with $0.36 \pm 0.01$ in animals deprived of antigen (Table III, experiments

Figure 6. Morphological studies on IgA-mediated acute lung injury. $(A)$ Representative section of lung from an animal that received 600 $\mu \mathrm{g}$ IgA antibody alone. There is absence of lung injury $(\times 300) .(B)$ Immunofluorescence detection of IgA in the lung of a rat that had been given $500 \mu \mathrm{g}$ IgA into the airway and antigen $(3.3 \mathrm{mg}$ DNPBSA) intravenously. Heavy IgA deposition is present in the alveolar septa $(\times 300)$. ( $C$ and $D$ ) Transmission electron micrographs of the

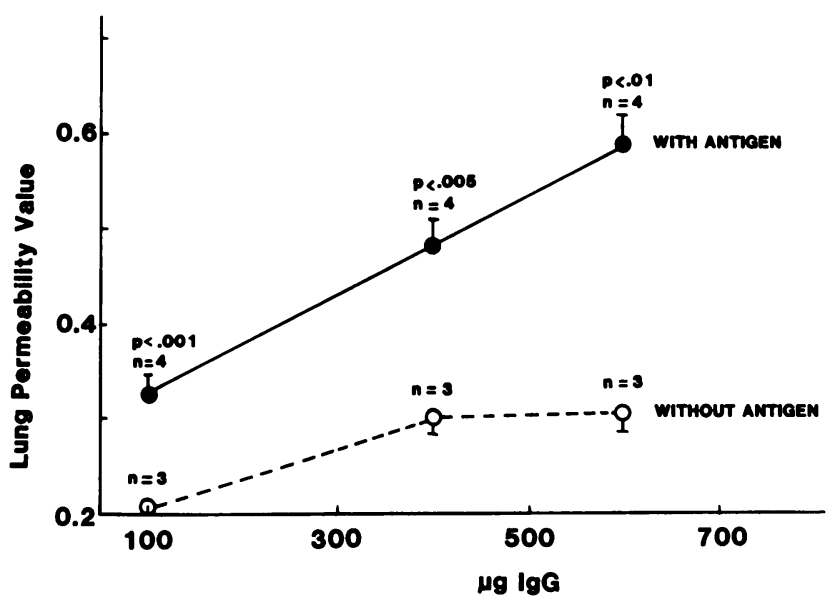

Figure 7. Dose-dependent acute lung injury with immune IgG immune complexes as assessed by lung permeability changes.

E and F). Not unexpectedly, in neutrophil-depleted animals, the ability of murine monoclonal IgG immune complexes to produce lung injury was markedly reduced, with a mean permeability value in four animals of $0.42 \pm 0.02$, whereas in complement-depleted animals the lung permeability fell to a mean value of $0.35 \pm 0.04$ (Table III, experiment E). These results should be compared with those from antigen-deprived animals, in which the lung permeability value was $0.32 \pm 0.01$, whereas in antigen-deprived animals also depleted of neutrophils this value was $0.32 \pm 0.01$ (Table III, experiment F). This indicates that neutrophil depletion leads to a $62 \%$ reduction in the intensity of lung injury when monoclonal IgG immune complexes were used, whereas in complement-depleted animals the same antibody produces a mean permeability value of $0.35 \pm 0.1$, which indicates complete protection against lung injury.

These data indicate that IgA immune complexes cause lung injury that is neutrophil independent but complement dependent, whereas lung injury produced by monoclonal IgG immune complexes is both neutrophil and complement dependent.

Comparative studies were carried out using rabbit polyclonal IgG antibody to BSA. The data are also shown in Table III (experiments $\mathrm{G}$ and $\mathrm{H}$ ), where lung permeability values of $1.09 \pm 0.03$ were found in neutrophil-intact animals. In contrast, in neutrophil-depleted animals, the mean lung permeability value fell to $0.27 \pm 0.01$, whereas in complement-depleted animals the mean permeability value was $0.46 \pm 0.03$, indicating 87 and $67 \%$

lungs of rats treated similarly to those described in $B$. There is intraalveolar hemorrhage and fibrin deposition with few identifiable neutrophils. Arrows indicates endothelial blebbing $(\times 750)$. $(E$ and $F)$ Higher magnifications of IgA-induced immune-complex lung injury showing erythrocytes and fibrin in alveolar spaces and blebbing of vascular endothelial cells (arrow) $(E, \times 2550 ; F, \times 3850)$. 


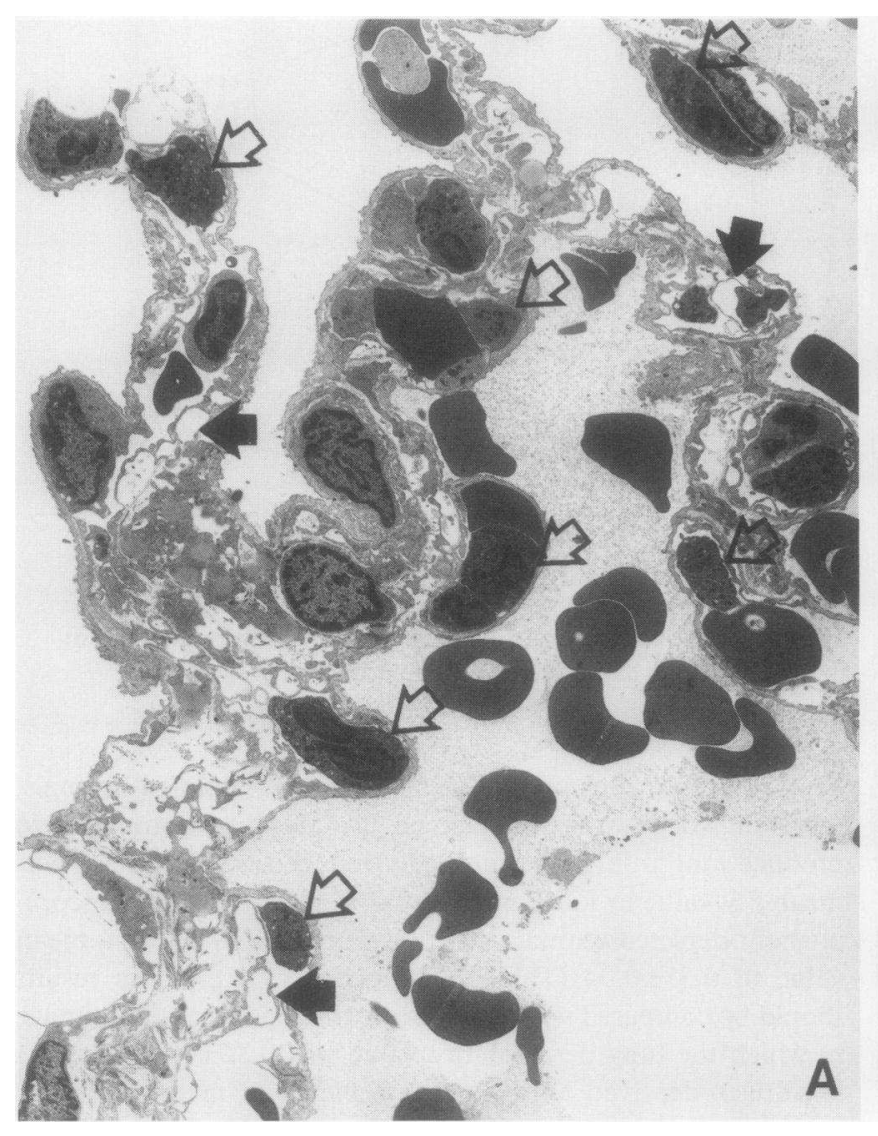

Figure 8. Morphological studies on IgG-mediated acute lung injury. $(A)$ Low power electron micrograph of lung from a rat given $500 \mu \mathrm{g}$ IgG into the airway followed by the intravenous administration of the antigen (3.3 mg DNP-BSN). There are numerous neutrophils

reduction, respectively. These findings with rabbit polyclonal IgG antibody confirm previous studies (4).

Morphometric studies of lung tissue. Morphometric analysis of plastic-embedded ( $1 \mu \mathrm{m}$ thick) sections of lung was undertaken to assess quantitative differences between animals developing acute lung injury induced by immune complexes containing IgA and IgG antibody. These data were then compared with those obtained from animals treated similarly but depleted of complement. We examined the lung interstitial capillary and the alveolar compartments; the data are summarized in Table IV, where either linear distances (in micrometers) reflecting surface areas or particle (cell) counts are recorded.

As is evident from the data, the interstitial capillary vessels in rats receiving saline into the airways showed little evidence of bleb formation $(1.06 \pm 0.48 \mu \mathrm{m} / 137.42 \pm 8.86 \mu \mathrm{m}$ of total surface measured, or $0.77 \%$ of total surface area). In contrast, those animals with lung injury due to either IgG or IgA-containing complexes showed a marked increase in endothelial blebbing

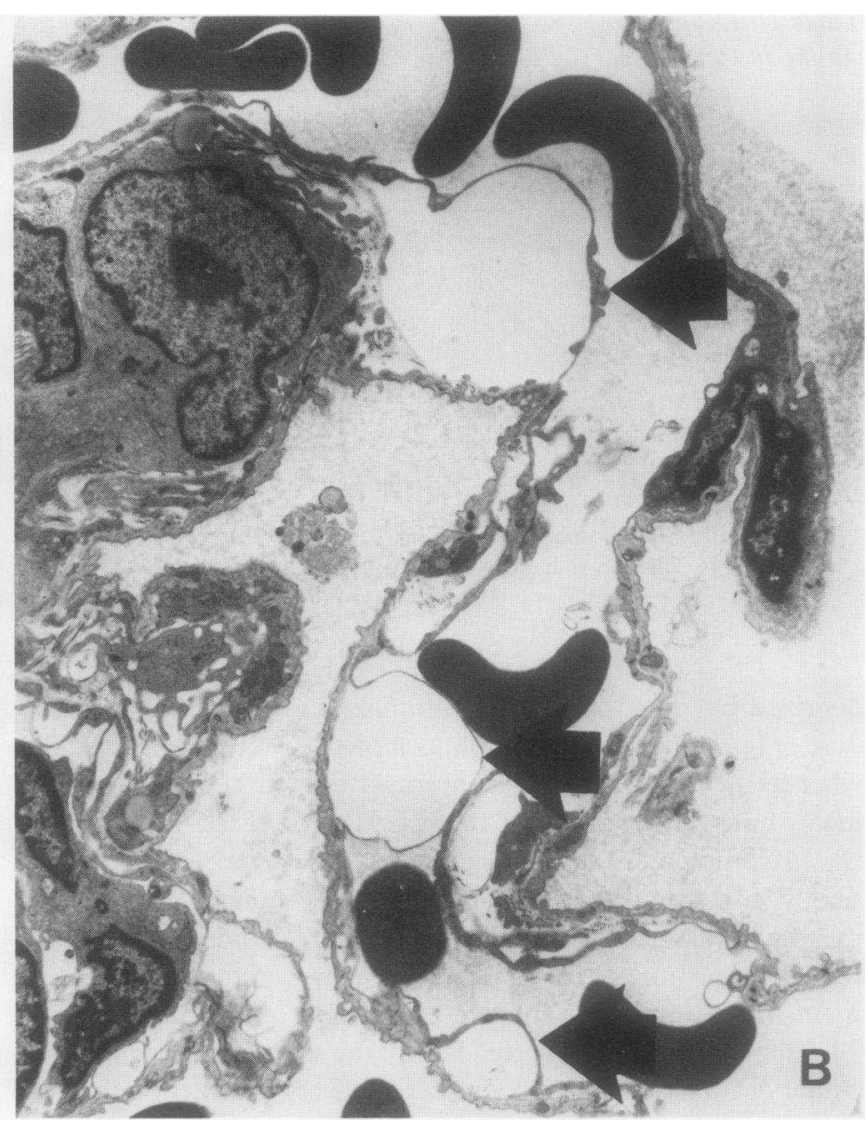

(open arrows) as well as areas of endothelial cell blebbing (closed arrows) $(\times 2080)$. (B) Higher power view of the same lung. There is extensive blebbing and lifting of the endothelial cells from the vascular basement membrane (arrows) $(\times 4480)$.

(11.83 $\pm 1.66 \mu \mathrm{m} / 147.6 \pm 12.2 \mu \mathrm{m}$ of total surface measured (or $8.01 \%$ of total surface area) for the $\mathrm{IgG}$, and $8.51 \pm 1.05$ / $127.4 \pm 7.73$ of total surface measured (or $6.67 \%$ of the total surface area) for the IgA complexes. In complement-depleted animals with lung deposition of IgA immune complexes, the degree of injury to the endothelial compartment of the lung was decreased fivefold as compared with that of the animals without complement depletion (endothelial cell blebbing was reduced to $2.08 \pm 0.65 / 135.7 \pm 6.36$, or $1.52 \%$ of the total surface area). The number of erythrocytes in alveoli of the complement depleted rats exposed to IgA-containing immune complexes, as expected, was also markedly decreased as compared with complement intact rats similarly exposed to IgA complexes $(1.7 \pm 65$ / $179.3 \pm 12.7$ vs. $7.3 \pm 2.4 / 209.41 \pm 13.0$ ). The numbers of neutrophils present in the interstitial capillaries were also reduced in the complement-depleted animals with IgA-containing immune complex deposits, from $1.63 \pm 0.03 / 44.19 \pm 3.24$ to $0.56 \pm 0.14 / 38.7 \pm 2.21$. Thus, these morphometric studies clearly 
Table III. Mediator Requirements for Lung Injury Produced by IgA and IgG Immune Complexes

\begin{tabular}{|c|c|c|c|c|c|c|}
\hline \multirow{2}{*}{$\begin{array}{l}\text { Experi- } \\
\text { ment }\end{array}$} & \multirow{2}{*}{$\begin{array}{l}\text { Antibody } \\
\text { source }\end{array}$} & \multirow{2}{*}{$\begin{array}{l}\text { Antibody injected } \\
\text { into airways } \\
\text { ( } 600 \mu \mathrm{g} \text { protein) }\end{array}$} & \multirow{2}{*}{$\begin{array}{l}\text { Antigen injected } \\
\text { intravenously }\end{array}$} & \multicolumn{3}{|l|}{ Status of animals } \\
\hline & & & & Normal & Neutrophil depleted & Complement depleted \\
\hline A & Murine & IgA (MOPC 460) & $\begin{array}{l}\text { DNP-BSA } \\
\quad(3 \mathrm{mg})\end{array}$ & $\begin{array}{l}0.67,0.84,0.75,0.74,0.86 \\
\quad 0.56,0.76,0.70 \\
(0.74 \pm 0.04) \S\end{array}$ & $\begin{array}{l}\text { Lung injurył } \\
0.89,0.65,0.83,0.75 \text {, } \\
0.66,0.68,0.56 \\
0.57,0.81 \\
(0.71 \pm 0.04)\end{array}$ & $\begin{array}{l}0.45,0.48,0.54 \\
(0.49 \pm 0.03)\end{array}$ \\
\hline B & Murine & IgA (MOPC 460) & None & $\begin{array}{l}0.32,0.36,0.38 \\
(0.35 \pm 0.02)\end{array}$ & $\begin{array}{l}0.24,0.25 \\
(0.25 \pm 0.01)\end{array}$ & \\
\hline $\mathrm{C}$ & Murine & IgA (MOPC 315) & $\begin{array}{r}\text { DNP-BSA } \\
(3.3 \mathrm{mg})\end{array}$ & $\begin{array}{l}0.64,0.63,0.78,0.54,0.53 \\
\quad 0.52,0.64 \\
(0.61 \pm 0.03)\end{array}$ & & $\begin{array}{c}0.37,0.40,0.42,0.42 \\
0.53,0.39,0.56 \\
0.37,0.50 \\
(0.43 \pm 0.02)\end{array}$ \\
\hline D & Murine & IgA (MOPC 315) & None & $\begin{array}{l}0.26,0.29,0.23,0.26,0.32 \\
(0.27 \pm 0.01)\end{array}$ & & \\
\hline $\mathrm{E}$ & Murine & IgG (MOPC, XRPC) & $\begin{array}{r}\text { DNP-BSA } \\
(3.3 \mathrm{mg})\end{array}$ & $\begin{array}{l}0.59,0.58,0.51,0.64,0.62 \\
0.70,0.68,0.48,0.70 \\
(0.62 \pm 0.03)\end{array}$ & $\begin{array}{l}0.44,0.45,0.44,0.37 \\
(0.42 \pm 0.02)\end{array}$ & $\begin{array}{l}0.46,0.30,0.40,0.24 \\
(0.35 \pm 0.04)\end{array}$ \\
\hline $\mathbf{F}$ & Murine & IgG (MOPC, XRPC) & None & $\begin{array}{l}0.35,0.37 \\
(0.36 \pm 0.01)\end{array}$ & $\begin{array}{l}0.32,0.31 \\
(0.32 \pm 0.01)\end{array}$ & \\
\hline G & Rabbit & IgG, anti-BSA & $\begin{array}{l}\text { BSA } \\
\qquad(10 \mathrm{mg})\end{array}$ & $\begin{array}{l}1.00,1.15,1.16,1.06,1.05 \\
1.02,1.21 \\
(1.09 \pm 0.03)\end{array}$ & $\begin{array}{l}0.32,0.26,0.18,0.30,0.29 \\
(0.27 \pm 0.01)\end{array}$ & $\begin{array}{l}0.40,0.54,0.45,0.47 \\
(0.46 \pm 0.03)\end{array}$ \\
\hline $\mathbf{H}$ & Rabbit & IgG, anti-BSA & None & $\begin{array}{l}0.13,0.15 \\
(0.14 \pm 0.01)\end{array}$ & & \\
\hline
\end{tabular}

* All murine antibodies were affinity purified from myeloma protein. The rabbit antibody was polyclonal IgG antibody to BSA. $¥$ Lung permeability values as described in text. Each number represents data from an individual animal. $\S$ Mean \pm SEM.

show that complement depletion affords protection against IgA immune complex-induced lung injury. This confirms the data obtained by the lung permeability studies.

\section{Discussion}

The results presented in this paper reveal that acute lung injury in the rat can be induced by the deposition of immune complexes containing IgA. This would appear to be the first report that IgA immune complexes have phlogistic potential for the lung, resulting in acute lung injury.

The concept that IgA complexes have a phlogistic capacity is an important one because of the postulated central role that IgA plays in mucosal immunity. There is a predominance of IgA in external fluids (including tracheobronchial fluids) compared with other immunoglobulins. Secretory IgA is felt to be an important first line of defense against infectious agents (20, $21)$ and it acts to complex with and eliminate foreign antigens $(22,23)$. Our study suggests that IgA, while playing an important protective function, also has the capability, under certain circumstances, to cause acute tissue injury in the lung. Thus, IgA is like IgG and IgM in that it has the dual capability to harm and to benefit the host.

The phlogistic potential of $\operatorname{IgA}$ immune complexes for the kidney has been demonstrated both clinically and experimentally. Certain types of human glomerulonephritis, namely, that associated with Henoch-Schönlein purpura as well as with idiopathic IgA nephropathy (Berger's disease), are characterized by a predominance of IgA deposits in the glomeruli and in involved vessels (8). In these diseases, the IgA complexes are usually associated with the presence of C3. Experimentally, glomerulonephritis can be induced with IgA-containing immune 
Table IV. Morphometric Analysis of Immune Complex-Induced Lung Injury

\begin{tabular}{|c|c|c|c|c|}
\hline \multirow[b]{2}{*}{ Treatment } & \multirow[b]{2}{*}{$\begin{array}{l}\text { Number } \\
\text { of sections }\end{array}$} & \multirow[b]{2}{*}{$\begin{array}{l}\text { Vascular compartment/ } \\
\text { Endothelial blebs (surface)* }\end{array}$} & \multicolumn{2}{|c|}{ Alveolar-interstitial compartment } \\
\hline & & & Neutrophilsł & Erythrocytes§ \\
\hline Saline alone & 30 & $\begin{array}{l}1.06 \pm 0.48 / 137.42 \pm 8.86 \\
(0.77 \% \text { surface area })\end{array}$ & $\begin{array}{l}0.3 \pm 0.097 / 55.61 \pm 4.03 \\
(1 \text { cell/185.36 } \mu \mathrm{m})\end{array}$ & 0.43 cells/alveolus \\
\hline $\mathrm{IgG}+\mathrm{DNP}-\mathrm{BSA}$ & 30 & $\begin{array}{l}11.83 \pm 1.66 / 147.6 \pm 12.2 \\
(8.0 \% \text { surface area) }\end{array}$ & $\begin{array}{l}1.85 \pm 0.17 / 56.31 \pm 4.48 \\
(1 \text { cell } / 30.3 \mu \mathrm{m})\end{array}$ & 11.16 cells/alveolus \\
\hline $\operatorname{IgA}+\mathrm{DNP}-\mathrm{BSA}$ & 31 & $\begin{array}{l}8.51 \pm 1.05 / 127.4 \pm 7.73 \\
(6.67 \% \text { surface area })\end{array}$ & $\begin{array}{l}1.63 \pm 0.03 / 44.19 \pm 3.24 \\
(1 \text { cell } / 27.1 \mu \mathrm{m})\end{array}$ & 7.3 cells/alveolus \\
\hline $\begin{array}{l}\text { IgA + DNP - BSA } \\
\text { after complement } \\
\text { depletion }\end{array}$ & 30 & $\begin{array}{l}2.08 \pm 0.65 / 135.78 \pm 6.36 \\
(1.52 \% \text { surface area })\end{array}$ & $\begin{array}{l}0.56 \pm 0.14 / 38.7 \pm 2.21 \\
(1 \text { cell } / 69.1 \mu \mathrm{m})\end{array}$ & 1.7 cell/alveolus \\
\hline
\end{tabular}

* Data are expressed as surface distance of endothelial bleb/surface distance (microns) of endothelial cells measured. ‡ Data are expressed as number of neutrophils/alveolar septal length (in microns). § Data are expressed as number of erythrocytes/alveolus with an average of 30 alveoli examined in each experiment.

complexes, leading to a glomerular proliferative response with the onset of hematuria (10). Therefore, in the kidney as well as in blood vessels, there is good evidence that IgA immune complexes can cause tissue injury in humans and in animals. Our findings extend the spectrum of the pathogenic role for IgAcontaining immune complexes.

The mechanism by which IgA immune complexes cause tissue injury appears clearly different than that for IgG-mediated tissue injury. IgG immune complexes, whether monoclonal or polyclonal, trigger tissue injury through the activation of the complement system with the subsequent attraction of neutrophils into the site of immune complex deposits. Neutrophils are responsible for the subsequent tissue injury, apparently through the generation and release of toxic oxygen products (7) and perhaps also by a role played by released lysosomal proteases. There is evidence that neutrophils, monocytes, and alveolar macrophages contain receptors to $\operatorname{IgA}(24,25)$, which would be consistent with our data showing the ability of IgA containing immune-complexes to activate neutrophils, resulting in production of oxygen-derived free radicals (Fig. 4). Further, there is evidence that $\operatorname{Ig} A$ in the polymeric form can react with human neutrophils in a manner that leads to the induction of chemotactic dysfunction (26). IgA-mediated acute lung injury described in this report requires the participation of the complement system to initiate the injury, but the tissue injury does not require the participation of neutrophils. The reason for the apparent disparity for a neutrophil requirement in IgA-mediated acute lung injury is unknown. The fact that acute lung injury due to deposition of IgA immune complexes still occurs in the absence of neutrophils makes the cell type responsible for the injury unclear. One candidate for the purveyor of lung injury would be the alveolar macrophage. Alveolar macrophages can be activated to produce significant amounts of oxygen-free rad- icals when presented with stimuli such as immune complexes (27). The hypothesis that alveolar macrophages may be involved in IgA-mediated acute lung injury could be related to the requirement for complement. IgA-containing immune complexes can activate complement, as shown in this study as well as another (28), although the complement activation activity is of a limited nature and may explain why other groups have had difficulty in detecting complement fixation (29). The amount of complement activation products such as $\mathrm{C} 5 \mathrm{a}$ or $\mathrm{C} 3 \mathrm{a}$ may be insufficient to attract neutrophils but adequate to bring about activation of alveolar and interstitial macrophages (30, 31). This activation might then lead to the generation of oxygen-derived free radicals, which are highly toxic for the lung (reviewed, 32).

The data in this paper suggest that IgA-containing immune complexes have lung-damaging activity and that the nature of this effect is related to a requirement for complement but not for neutrophils. This is distinctly different from the manner in which IgG-containing immune complexes bring about tissue injury. The recognition that acute tissue injury can be provoked by a role for complement exclusive of the neutrophil represents a novel immunopathological mechanism that is as yet unexplained.

\section{Acknowledgment}

This work was supported in part by National Institutes of Health grants HL-28442, HL-26809, and GM-29507, and a grant from the Council for Tobacco Research.

\section{References}

1. Dreisin, R. B., M. I. Schwarz, A. N. Theofilopoulos, and R. E. Stanford. 1978. Circulating immune complexes in the idiopathic interstitial pneumonias. N. Engl. J. Med. 298:353-357. 
2. Schwarz, M. I., R. B. Driesen, D. S. Pratt, and R. E. Stanford. 1978. Immunofluorescent patterns in the idiopathic interstitial pneumonias. J. Lab. Clin. Med. 91:929-938.

3. Inoue, T., Y. Kanayama, A. Ohe, N. Kato, T. Horiguchi, M. Ishii, and K. Shiota. 1979. Immunopathologic studies of pneumonitis in systemic lupus erythematosus. Ann. Int. Med. 91:30-34.

4. Johnson, K. J., and P. A. Ward. 1979. Acute immunologic pulmonary alveolitis. J. Clin. Invest. 54:349-357.

5. Roska, A. K., J. C. Garancis, V. L. Moore, and P. Abramoff. 1977. Immune complex disease in guinea pig lungs. I. Elicitation by aerosol challenge, suppression with cobra venom factor, and passive transfer with serum. Clin. Immunol. Immunopathol. 8:213-224.

6. Scherzer, H., and P. A. Ward. 1978. Lung injury produced by immune complexes of varying composition. J. Immunol. 121:947-952.

7. Johnson, K. J., and P. A. Ward. 1981. Role of oxygen metabolites in immune complex injury of lung. J. Immunol. 126:2365-2369.

8. Berger, J. 1969. IgA glomerular deposits in renal disease. Transplant Proc. 1:939-944.

9. Baart de la Faille-Kuyper, E. H., L. Kater, C. J. Kooiker, and E. J. Dorhaut. 1973. IgA deposits in cutaneous blood vessel walls and mesangium in Henoch-Schönlein syndrome. Lancet. I:892-893.

10. Rifai, A., A. S. Parker, P. O. Teague, and E. M. Ayoub. 1979. Experimental IgA nephropathy. J. Exp. Med. 150:1161-1173.

11. Emancipator, S. N., G. R. Gallo, and M. E. Lamm. 1983. IgAimmune complex renal disease induced by mucosal immunization. Ann. NY Acad. Sci. 409:171-176.

12. Cochrane, C. G., H. J. Müller-Eberhard, and B. S. Aiken. 1970. Depletion of plasma complement in vivo by a protein of cobra venom: its effects on various immunologic reactions. J. Immunol. 105:55-69.

13. Ward, P. A., G. O. Till, R. Kunkel, and C. Beauchamp. 1983. Evidence for role of hydroxyl radical in complement and neutrophildependent tissue injury. J. Clin. Invest. 72:789-801.

14. Ward, P. A., R. E. Duque, M. C. Sulavik, and K. J. Johnson. 1983. In vitro and in vivo stimulation of rat neutrophils and alveolar macrophages by immune complexes. Am. J. Pathol. 110:297-309.

15. Ritchie, R. F., and R. Smith. 1976. Immunofixation. I. General principles and application to agarose gel electrophoresis. Clin. Chem. 44:497-499.

16. Eisen, H. N. 1964. Preparation of purified anti-2,4-dinitrophenol antibodies. Methods Med. Res. 10:94-102.

17. Claflin, J. L. 1976. Uniformity in the clonal repertoire for the immune response to phosphorylcholine in mice. Eur. J. Immunol. 6:667694.

18. Potter, M. 1977. Antigen binding myeloma proteins in mice. Adv. Immunol. 25:141-211.

19. Laemmli, V. K. 1970. Cleavage of structural protein during the assembly of the head of the bacteriophage T4. Nature (Lond.). 227:680685 .

20. Perkins, J. C., H. L. Knopf, A. Z. Kapikian, and R. M. Chanock. 1969. The relative role of serum and nasal secretory neutralizing antibodies in protection against experimental rhinovirus illness. In The Secretory Immunologic System. National Institute of Child Health and Human Development, Bethesda, Maryland. 203-214.

21. Fubara, E. S., and R. Freter. 1973. Protection against enteric bacterial infection by secretory IgA antibodies. J. Immunol. 111:395403.

22. Russell, M. W., T. A. Brown, R. Kulhavy, and J. Mestecky. 1983. IgA mediated hepatobiliary clearance of bacterial antigens. Ann. NY Acad. Sci. 409:871-872.

23. Williams, R. C., and R. J. Gibbons. 1972. Inhibition of bacterial adherence by secretory immunoglobulin A: Mechanisms of antigen disposal. Science (Wash. DC). 177:697-699.

24. Fanger, M. W., S. N. Goldstine, and L. Shen. 1983. The properties and role of receptors for IgA on human leukocytes. Ann. NY Acad. Sci. 409:552-562.

25. Gauldie, J., C. Richards, and L. Lamontagne. 1983. Fc receptors for IgA and other immunoglobulins on resident and activated alveolar macrophages. Mol. Immunol. 20:1029-1037.

26. Van Epps, D., and R. C. Williams, Jr. 1976. Suppression of leukocyte chemotaxis by human IgA myeloma components. J. Exp. Med. 144:1227-1242.

27. Ward, P. A., R. E. Duque, M. C. Sulavik, and K. J. Johnson. 1983. In vitro and in vivo stimulation of rat neutrophils and alveolar macrophages by immune complexes. Production of $\mathrm{O}_{2}^{-}$and $\mathrm{H}_{2} \mathrm{O}_{2} . A m$. J. Pathol. 110:297-309.

28. Pfaffenbach, G., M. E. Lamm, and I. Gigli. 1982. Activation of guinea pig alternative complement pathway by mouse IgA immune complexes. J. Exp. Med. 155:231-247.

29. Colten, H. R., and J. Bienenstock. 1974. Lack of C3 activation through classical or alternate pathways by human secretory IgA anti blood group A antibody. In The Immunoglobulin System. J. Mesticky and A. R. Larson, editors. Plenum Publishing Corp., New York. 305308.

30. Hartung, H. P., U. Hadding, D. Bitter-Suermann, and D. Gemsa. 1983. Stimulation of prostaglandin $E$ and thromboxane synthesis in macrophages by purified C3b. J. Immunol. 130:2861-2865.

31. Hartung, H. P., D. Bitter-Suermann, and U. Hadding. 1983. Induction of thromboxane release from macrophages by anaphylactoxic peptide C3a of complement and synthetic hexapeptide C3a 72-77. $J$. Immunol. 130:1345-1349.

32. Fantone, J. C., and P. A. Ward. 1982. Role of oxygen-derived free radicals and metabolites in leukocyte-dependent inflammatory reactions. Am. J. Path. 107:397-417. 